\title{
The role of regulatory learning in energy transition: The case of solar PV in Brazil
}

Miguel Vazquez ${ }^{*}, a, b, c$ and Michelle Hallack ${ }^{a, c}$

a NIETI - Universidade Federal Fluminense (UFF). Campus do Gragoatá - Bloco F - São Domingos - NiteróiRio de Janeiro, Brazil - CEP: 24210-350.

b IEFE - Bocconi University. Via Röntgen, 1, 20136, Milan, Italy. tel: +39 0258363820

c Florence School of Regulation, RSCAS, European University Institute. Via delle Fontanelle, 19, 50014 Firenze, Italy.

${ }^{*}$ Corresponding author

Email addresses Miguel Vazquez: miguel.vazquez.martinez@gmail.com

Michelle Hallack: michellecmhallack@gmail.com 


\section{Abstract}

An important problem that has attracted significant amount of attention within the context of energy transitions is the carbon lock-in: a situation in which energy systems are locked-in to high carbon technologies through a path-dependent process. Several measures to avoid the carbon lock-in involve technology-specific measures, which in turn implies that those measures may result in an energy system locked-in to certain low carbon technologies. We consider that the Brazilian system needs policies to escape the carbon lock in, which are based on providing incentives to low carbon technologies. We develop an analytical framework to analyze the role of regulatory institutions in the possible lock-in to utility-scale photovoltaic, in the sense that they create barriers to the adoption of distributed-generation photovoltaic. We show that the definition of a process to adapt the institutional framework in a context of stress in the innovation system is crucial for the adoption of new technologies. Applying our framework to the Brazilian power sector, we observe that only when regulators consider the possibility that the system is locked-in to centralized production technologies (and not when they just consider the carbon lock-in) they manage to eliminate barriers to distributed generation based on solar PV.

Key words: Energy transitions; Institutional evolution; Path-dependence; Evaluative criteria.

JEL: L43; L94; 031; 043.

\section{Introduction}

The electricity industry has taken center stage in the transitions to economies based on low carbon technologies. In this paper, we are concerned with the challenge of designing measures to facilitate transitions to low carbon electricity systems. The adopted measures are the result of a framework that establishes, among other dimensions, the objective of the particular policy -along the lines of the theory of economic policy, (Tinbergen, 1952). One controversial aspect regarding the definitions of policy objectives within the energy transitions context is whether policies should be technology-specific. The discussion may be motivated from the fact that different policies respond to different objectives, (Gawel et al., 2017). Thus, depending on whether technology evolution is considered or not, the importance of 
industrial and technology policies have more or less importance in the design of policies to facilitate energy transitions.

This paper is framed by an evolutionary view of both technological and institutional development, along the lines of (Foxon, 2011). This co-evolutionary thinking deals with the fact that, on the one hand, policy objectives might change when technology practice changes. On the other hand, if policy objectives are too rigid, they may create circumstances under which technologies might be in the market even though they are inferior to other technologies. We will term this situation as lock-in, (Arthur, 1989). One of the less explored consequences of the co-evolutionary framework is that policies are rarely implemented by external, fully rational rule-makers. That is, rule-makers do not decide using deductive, rational reasoning but they use inductive reasoning instead, (Arthur, 1994). Specifically, we represent that rulemakers, in a context of significant complexity, understand reality through simplified models that are then used to perform deductions. Such simplified models may be interpreted as beliefs. Rule-makers also obtain feedback from the complex environment, which allows them to modify decisions according to their beliefs (their simplified models). In order to develop an analytical framework to analyze energy transitions that takes account of the previous situation, we use the Institutional Analysis and Development (IAD) framework, (Ostrom, 2009). In the IAD, the main drivers to change rules are the 'evaluative criteria' applied to outcomes. We connect the idea of evaluative criteria to rule-makers' beliefs in order to define how institutions change.

Our study is placed within the context of energy transitions, which can be understood as processes to make energy systems less dominated by fossil-fuel technologies. In order to understand potential paths for transitions to low carbon energy systems, it is necessary to analyze the design of energy policies, which are based on specific assumptions on the behavior of the power industry.

One very common view is identifying energy transitions with an externality problem associated with climate change, (Pérez-Arriaga and Linares, 2008). In this context, the objective is to design mechanisms that internalize the externality, hence the reasoning suggests the use of technology-neutral schemes, 
(European Commission, 2014a). In that context, energy policies are often analyzed in terms of just prices and/or installed capacities, see for instance (Haas et al., 2011) for a historical perspective of support mechanisms, (del Río and Linares, 2014) for an analysis of auction-based methods, or (Lopez-Polo et al., 2012) for a specific application to photovoltaics.

The previous "environmental-externality" point of view may be complemented by the consideration of innovation externalities, i.e. the positive externalities created by innovation, (Jaffe et al., 2005). This makes less obvious the case for technology-neutral policies, which likely motivates that the European Commission also finds justification for technology-specific schemes, e.g. (European Commission, 2014b). This point of view may be identified with "technology market failures", (Gawel et al., 2017).

The two previous descriptions of the transition problem are based on identifying externalities, which implies a static representation of the industry, (Witt, 1996). Evolutionary economics depart from the externality-based reasoning and consider an out-of-equilibrium process ${ }^{1}$ to represent energy transitions, see for instance (Foxon, 2011) or (Nill and Kemp, 2009). Our paper is placed within this view, as regulatory learning is better understood as a dynamic process. The evolutionary standpoint implies taking into account that one groups very different policies under the header "policies to incentivize renewable energy sources". This is a consequence of the fact that not all policies to promote renewable production are designed to fulfill the same objective. To see this, one may consider the "complex value" approach for business model analyses introduced in (Hall and Roelich, 2016), where motivations such as competitiveness, self-governance, environmental concerns, reduction of fuel poverty, etc. are identified as drivers for actors in the energy system. Another recent example can be found in (Bauwens, 2016), where motives for investment in renewable energy technologies in energy communities are analyzed in depth.

\footnotetext{
${ }^{1}$ We will review the economics behind this point of view in section 3.1.
} 
Considering this complex interaction among actors require considering the institutional dimension of the problem. In this regard, (Jacobsson and Lauber, 2006) explains the institutional dynamics behind the German introduction of low carbon technologies. In particular, regulatory frameworks are pointed out as a central driver of the transition. Recently, (Iychettira et al., 2017) propose an institutional analysis to simulate the construction of renewable policies using agent-based models. Hence, representing technological dynamics together with complex policy objectives highlights the need for a multi-level description of the transition process. In this paper, we will describe energy industries as large systems with multi-layered interactions, where technological evolution (including innovation policies) are relevant to understand industry dynamics. To that end, we propose to use a co-evolutionary framework, (Foxon, 2011). This has been also the choice of other recent applications to energy industry studies. (Bolton and Foxon, 2013) use co-evolutionary thinking to analyze business models at the retail level in GB, pointing at the fact that some regulatory actions (consumers' right to switch supplier) constrain the innovation in both consumers' profiles and low carbon generation options. Along the same lines, (Giordano and Fulli, 2012) shows that smart meters and electric vehicles may facilitate the development of new distribution business models by creating opportunities to capture new complex values in the entire system.

The previous literature shows the importance of the design of the regulatory framework in the dynamics of the energy industry. From this point of view, we complement the literature by analyzing the dynamics associated with rule making. Specifically, we highlight one element that has received relatively little attention: the process to change rules-in-use ${ }^{2}$ should be a robust one in order to allow proper institutional learning. To that end, we build a framework that represents the dynamics of institutional

\footnotetext{
${ }^{2}$ (Crawford and Ostrom, 1995) provides a thorough analysis on the definition of rules. According to it, we use the definition of rules as prescriptions of what players involved "must" do, "must not" do, or "may" do, and the associated sanctions in case rules are not followed.
} 
adaptation, where rule-makers will adapt, after observing industry outcomes, according to their assessment of whether outcomes match their objectives (evaluative criteria).

In summary, in order to understand the coevolution between institutions and technology in the energy industry, it is necessary to consider that:

- Institutions interact with technology

- Different layers of the decision-making process interact among them

- Policy implementation is done through multiple layers that include regulation

We apply the previous reasoning to the analysis of the Brazilian electricity system. The base case in our study is the view that the Brazilian system needs policies to escape the carbon lock in. Specifically, the focus of our study is to investigate the mechanisms by which regulatory institutions may lock in the system to utility-scale technologies. From the technological point of view, the most studied problem is the carbon lock in, (Unruh, 2000): a situation in which energy systems are locked in to high carbon technologies through a path-dependent process. But several measures to avoid the carbon lock-in imply technology-specific measures, (Nill and Kemp, 2009), which in turn may lock in the energy system to certain low carbon technologies.

Such policies are based on giving incentives (regardless the particular mechanism to implement the incentives) to low carbon technologies. In order to understand the potential for lock in, it is important to consider that Latin American countries have been examples of significantly centralized implementations of market arrangements, (Hammons et al., 2011)3. Most of the justifications for those centralized market arrangements imply the idea of centralized generation of electricity through large power plants. At the same time, during the last years, the optimal technical solution to produce electricity has become less clear. In particular, solutions to produce electricity in a decentralized manner have become increasingly

\footnotetext{
${ }^{3}$ Note that the trend currently observed in Europe, and to some extent in the US, is to implement more centralized solutions.
} 
attractive. The question that arises in that context can be posed as: can this decentralized technology enter into centralized market arrangements, even if these market arrangements contain policies to facilitate investment in low carbon technologies? The answer may depend on the particular rules governing the sector.

We restrict our attention to the case of solar PV in Brazil, where the institutional framework for power generation (based on a centralized market design) contains barriers for distributed generation to enter the market. If rule-makers do not adapt to changing technologies, solar generation will (potentially) be locked in to utility-scale PV technologies precluding the entrance of distributed solar PV. To that end, we develop a system dynamics framework along the lines of (Forrester, 1968) to model the Brazilian electricity sector. The analysis of regulators' response is based on the identification of different evaluative criteria (different policy objectives) that are used to analyze the need for adaptation. That is, if the outcome of market players' investment decisions does not fulfill the policy objective they sought, they will change the rules to improve the outcome. We consider three types of policy objectives. In the first case regulators observe only that electricity is produced by the cheapest available technology nowadays. This a representation of regulators not considering technological dynamics. In the second case regulators are concerned with technological dynamics, but they only consider the introduction of solar PV through niche markets. In the third case regulators are concerned with technology development and consider the possibility of lock in to centralized technologies. Hence, we show that the definition of a process to adapt the institutional framework in a context of stress in the innovation system is crucial for the adoption of new technologies.

This paper is organized as follows. After this introduction, section 2 analyzes the main elements of the Brazilian regulatory framework that will be used for the study, as well as the current situation of the solar PV in Brazil. Section 3 will develop our analytical framework, first building on economic theory and then applying the theory to develop a simulation model to represent power system dynamics. Section 4 analyzes the corresponding numerical results. Section 5 concludes and identifies relevant policy implications. 


\section{The Brazilian context}

In this section, besides describing the most important characteristics of the Brazilian regulation, we look at the current state of development of solar PV. The aim is providing a broad picture of the system we will study in section 3 .

\subsection{Current state of solar PV in Brazil}

Because we will study different possible paths, a discussion of the starting point of such paths is relevant. In particular, we will assume that no solar PV is already installed in the Brazilian system. In this subsection, we describe the current development of solar PV in the Brazilian system to provide underpinning for the adopted description in the case study.

At present, the total solar PV capacity installed in the Brazilian system is still limited. Before June 2017, the total capacity added up to $23 \mathrm{MW}$. Of those, only two utility-scale projects were installed: Fontes Solar I and Fontes Solar II, both with capacity of 5 MW (Enel Green Power was the company responsible for the investment. In June 30th 2017 , four additional plants (which were contracted in dedicated auctions, see section 2.2.2) entered into operation, each with capacity of $30 \mathrm{MW}$ : Bom Jesus da Lapa I and II, and Lapa 2 and 3 (of Enel Green Power). Nowadays, total PV capacity is 148 MW, 130 MW of which are produced from utility-scale PV, (ANEEL, 2017a, 2017b).

Solar PV is part of an effort to introduce RES in the Brazilian generation mix. The plan is to install 7000 MW before 2024, (EPE, 2014b). The chosen support mechanism is dedicated tendering, (EPE, 2012b).

Among the companies that won the three auctions involving solar PV, LER 08/2014, LER 08/2015 and LER $09 / 2015$, the four main companies together have $52.12 \%$ (49 plants) of all solar power plants and $54.13 \%(1,419.9 \mathrm{MW})$ of all installed capacity.

Table 1 depicts this situation. Those are: the Italian group Enel; Canadian Solar Inc; Lintran do Brasil Participações S.A., a subsidiary of a Spanish company; and the French Solairedirect. The French company 
Électricité de France (EDF) is also present in some consortia alongside Canadian solar Inc. There was over 4 billion dollars of planned investment involved with the solar power plants, with over $50 \%$ allocated in the top four companies. The contracted capacity was expected to enter into operation between 2017 and 2019 (ANEEL, 2016; Reuters Brasil, 2016).

Table 1 - Contracted capacity of solar PV at LER auctions 2015-2016. Source: (Andreao et al., 2017).

Therefore, between 2014 and 2015, solar PV was successfully inserted into the auctions in Brazil. However, there is evidence that the set of mechanisms put in place are not working as expected.

Figure 1. Solar PV capacity regarding its schedule to enter into operation - MW - November 2015 to July 2017 Brazil. Source: (Andreao et al., 2017).

From Figure 1 it is clear that, even if the number of power plants (and capacity) is rising, schedule is becoming problematic. For the first time, the number and capacity of solar PV power plants with a delayed scheduled has surpassed the power plants on schedule: as of July 2017, the solar PV capacity on schedule and with a delayed schedule are 1041.36 MW (41 plants) and 1745,07 MW (59 plants) respectively.

In summary, even if contracted capacity is increasing, there are reasons to be cautious with the viability of those projects. The Argentinian experience shows that, even if PPAs are allocated, financing difficulties may appear and they may represent an effective barrier to new generation development.

\subsection{The regulatory framework in Brazil}

The regulatory framework of the Brazilian power system can be understood as consequence of the amount of hydro generation, of the characteristics if this technology, and of the historical evolution of the 
Brazilian reform and crises. The result is a set of market arrangements built on centralized choices, (Tolmasquim, 2012). First we will describe the mechanisms and then we will identify barriers to distributed PV generation. Level-shifting strategies will be a process set up to change regulation and alleviate those identified barriers.

\subsubsection{General mechanisms}

One of the most important points of this paper is that specific institutions play a central role in the dynamics of power industries. In particular, the adoption of generation technologies might be crucially affected by the institutional design. The aim of this section, hence, is to point out the basic characteristics of the Brazilian institutional setting. To that end, we will consider four basic sets of activities in an electricity industry, each of which will be coordinated by a specific set of institutions involving different sets of agents: planning, procurement, short-term operation and retailing. Note that these sets of activities are not related to the previous dynamic levels but to groups of activities involving different groups of equipment.

- Planning - Planning based on the combination of a central planner studies, which uses as input distribution companies forecasts. Specifically, distribution companies are required to forecast the consumption of their consumers. Distribution companies are strongly incentivized to perform this forecast accurately, as they will face penalties for both over- and under-estimate their electricity requirements.

After that, all those forecasts are coordinated with the rest of the relevant data by the Empresa de Pesquisa Energética (the energy planning company). EPE is public enterprise attached to the Energy and Mines Ministry that determines administratively the long-term planning of the electricity industry. Finally, distribution companies are required to contract with power producers all the energy (and capacity) needed to serve their customers.

- Procurement - The central coordination mechanism between power producers and the system operator is a long-term contract (often called Power Purchase Agreement in the power systems 
literature). It establishes the obligation for power producers to generate the amount of electricity the system operator decides at each point in time, up to the total amount contracted. Nonetheless, there are several types of procurement schemes depending on: (i) the amount of energy consumed by customers; (ii) the characteristics of power plants and (iii) whether the power plant is existing or new.

As for the former aspect (i), if consumers are "too small" (less than $3 \mathrm{MW}$ ), they are required to procure their electricity consumption through a single buyer. Otherwise, they are allowed to contract directly with a power producer. In any case, all consumption is required to be ensured by a contract. As for the of power plant characteristics (ii), the auctions may differentiate directly according to the power plant technology and the time scope of the contract. As for the latter aspect (iii), when new generation is required (according to the long-term planning), the national regulator ANEEL organizes auctions where potential new power plants competes for the market in price. The winner(s) enters into Power Purchase Agreements. Existing plants sell their energy either through specific auctions for existing capacity or through contracts with large customers.

- Short-term system operation - After the long-term contracts are established, a central system operator (ONS) takes control of the entire system, including generation assets. All production is decided by the use of an optimization model that decides the dispatch. Differences between energy contracted and actual physical production is cleared at a price calculated by the optimization model. This optimization model decides also inter-temporal opportunity costs associated with hydro generation.

- Retailing - Besides regional distribution companies, which sell electricity through the PPAs, retailers can compete for large customers over $3 \mathrm{MW}$ (about a quarter of the market without interaction with the single buyer, in terms of energy consumption).

\subsubsection{Incentives for distributed generation in Brazil}

Distributed generation, the term often used to refer to relatively small power plants usually connected to the distribution network (the "low-voltage" network), is difficult to include in the previous institutional setting. The main reason is that the PPA-based model described above work better when the plants 
involved are large engineering projects. It is more complicated when public tenders are required to build and operate small projects.

In fact, regulation has adapted to the particular features of distributed generation over time. For instance, the Decree 5.163/04 (which created the figure of Distributed Generator), established a different contracting environment for it: distributed generation would sell energy to distribution companies, instead of using auctions, using a public tender organized by the distribution company. In any case, the energy price would still be the regulated tariff that distribution companies apply to electricity. In the case that they opt for selling to large consumers, they would be subject to the complex rules governing bilateral contracts. In that view, even with the simplified contracting environment, distributed generation faced differentiated incentives.

In order to facilitate the development of distributed generation, ANEEL issued the Resolution 482 (“Resolução Normativa 482, ANEEL"), which regulated micro- and mini-distributed generation. Two central incentives are introduced in this resolution. On the one hand, a measure often called "net metering" is introduced. Micro and mini photovoltaic generators can avoid paying for the amount of electricity they generated, thereby reducing the value of the electricity bill in the amount equivalent to the final energy price that its distribution company charges. In practice, the distributed generator obtains a return as savings in the electricity bill. The advantage of this system is that savings are associated with the final consumer price, which is significantly higher than the price in energy auctions.

Besides, Resolution 482 defined extensively the procedures to access the distribution network, which are central in the facilitation of distributed generation (the one connected to the distribution network). Actually, one of the main aspects of access to the distribution network is to define who should bear the additional costs associated with connecting distributed generation. In order to facilitate its insertion, the Resolution 482 defined that the distribution company will be responsible for the impact analysis and the associated costs (including the bidirectional meter required to implement net metering). After that, ANEEL issued Resolution 687/2015, which amended Resolution 482/2012. In it, more stress was put in 
the definition of distributed generation (micro- and mini-generation). It may be viewed as a continuation of the previous REN 482, enhancing definitions for distributed generation and related procedures. The evolution of these resolutions might be seen as the beginning of the regulatory learning we describe in this paper.

Finally, the possibilities of specific financial aid for distributed generation in Brazil are limited. Although there exists some localized funds, the main financial institution for the construction of power plants (the Brazilian development bank, BNDES) has no specific product for distributed generation.

- Incentives faced by distributed generation - In this section, our objective is to develop a comparison between large solar power plants and distributed photovoltaic generation.

Table 2. Comparison between incentives for Large Power Plants and Distributed Photovoltaic generation. Source: (Mello, 2014).

From the analysis of the table above, one may observe that all aspects are negative to the distributed generation, except the one associated with environmental licensing (second point under "planning"). That means that distributed generation, in fact, is actually facing barriers when compared to larger power plants.

As, in this paper, we are concerned with the choice of technology, the incentive system in the current Brazilian power system clearly favors the introduction of utility-scale PV over distributed-generation PV.

\section{Methodology}

This section aims at describing the framework for our study. Subsection 3.1 uses economic theory to define the abstract building blocks of our methodology. Subsection 3.2 applies the previously developed ideas to the case of electricity industries. Subsection 3.3 describes our modeling strategy to implement the framework described in the previous two subsections. 


\subsection{Using economic theory to build an analytical framework}

When technology is not perfectly defined, the assumptions on which the theory of regulation is built represent reality with less accuracy. There is a new set of problems that have received relatively little attention: it is not just about using already available resources in an efficient manner but also about creating resources, so the dynamic aspects of efficiency cannot be disregarded. In that context, although regulation becomes evolutionary, the level of detail with which regulatory institutions are represented in evolutionary studies is still moderate, see for instance (Perez, 2009). Our analytical framework aims at combining two layers of reasoning:

- Layer 1 - Regulation and its evolution emerge from a complex interaction between rule-makers and industries

- Layer 2 - Evaluative criteria are the drivers of industry structural change, including change of regulatory institutions

\subsubsection{Layer 1 - Regulation as an evolutionary process}

This paper is concerned with the evolution of rules. It uses the definition of rules provided in (Crawford and Ostrom, 1995): rules are prescriptions of what players involved "must" do, "must not" do, or "may" do, and the associated sanctions in case rules are not followed. One particular case of those rules is the regulatory framework. This paper's aim is the analysis of the fundamental elements of the dynamic process defining changes in the regulation of the energy sector. In this regard, the paper considers that rules are not, in general, the result of a static, rational decision-making process, but they are emergent properties of the complex interaction between rule-makers and industries. A key point of that representation is considering bounded rationality in the process of making rules: rule-makers do not decide using deductive, rational reasoning but they use instead inductive reasoning, (Arthur, 1994). Specifically, the representation adopted in this paper is that rule-makers, in a context of significant complexity, understand reality through simplified models that are then used to perform deductions. Such deductions may be interpreted as beliefs. Rule-makers also obtain feedback from the complex 
environment, which allows them to modify decisions according to their beliefs (their simplified models). This representation can be understood in the context of (Simon, 1959): rule-makers follow 'satisficing' routines, i.e. they will only change routines in the case that outcomes are no longer satisfactory. This level of satisfaction depends on the evaluative criteria used by rule makers. Consequently, the criteria that trigger regulatory change (evaluative criteria) should be analyzed in depth because it may provide the required predictability to market players.

\subsubsection{Layer 2 - Institutional change and technological evolution}

The next level of analysis considers that rules shape technology but also that technology shapes rules. The basic frame is given by (Künneke, 2008). It identified the relevance of two sets of multi-level group of activities: the institutional levels as identified by (Williamson, 1998) and the technology practice levels defined by (Künneke, 2008) building on (Dosi, 1982).

We are concerned with the dynamics of the previous decision-making process. In that context, we note that a large part of the study of institutions is concerned with the idea of efficient coordination, where institutions are introduced in order to align incentives and deal with conflict, (Langlois and Robertson, 2002). Nonetheless, as highlighted in (Langlois and Robertson, 2002), another critical functions to be performed is the coordination of resources, not only of incentives. To perform those functions, players (frequently firms) create a set of productive routines, which constitutes their capabilities. From that point of view, the kind of game that describes the previous decision-making process is the "coordination game". Hence, we may identify the first kind of problem ("conflict" situations) with the ones primarily studied in the context of institutional economics. The second kind of problem ("coordination" situations) is studied within the literature on technological practice. Our analytical framework will combine both streams of literature in order to understand the joint evolution of institutions and technology. To that end, we will look at a framework where all those kinds of games can be analyzed jointly: the Institutional Analysis and Development framework defined by (Ostrom, 2009). 
Table 3. Relationship between action situations and institutional and technological levels. Source: Own elaboration, based on (Ostrom, 2009), (Williamson, 1998) and (Künneke, 2008).

In the first column of Table 3, we represent the different levels of action situations, as defined by (Ostrom, 2009). The basic idea behind an action situation is very close to the definition of a transaction in (Williamson, 1998). Together with the rules of the game, which can be thought of as the structure of the action situation, they form an action arena. This general framework can describe both the institutional levels developed in (Williamson, 1998) and the technological levels developed in (Künneke, 2008). The correspondence is represented in Table 3.

One of the insights provided by the Institutional Analysis and Development framework is that, even if the decision-making process of the four situation levels is nested (e.g. decisions at the operational level are framed by decisions at the collective-choice level), level-shifting strategies are crucial to understand the evolution of institutions. In this paper, we will include in this interpretation the importance of levelshifting to understand the evolution of technologies. From this paper point of view, we restrict ourselves to considering the relationship between the constitutional-choice level (where regulation is designed) and the collective-choice level (where governance is designed). Hence, a player will be choosing levelshifting strategies when she begins to consider the change of any of the constraints on the collectivechoice level. The way the outcome impacts the choice of level-shifting strategies depends on the evaluation criteria.

\subsection{Applying the analytical framework to study lock-in within energy systems}

We begin by identifying the nested levels in our application. In particular, we will consider the interaction between two levels.

- Interaction \# 1: Constitutional level within the context of energy transitions - The first situation is associated with what was called the constitutional level (both institutional environment and technological trajectory). In it, two types of actors make decisions. On the one hand, rule-makers decide 
on the regulatory framework. This includes, among other decisions, the design of market arrangements: who is able to sell, purchase or contract services (e.g. transmission services), what are the possible mechanisms to establish those contracts, who is in charge of developing the system, etc. It also includes decisions on the way in which dedicated financial lines can be accessed. On the other hand, firms make decisions regarding technological choices. R\&D activities and the development of capabilities related to energy technologies are made at this stage. This involves whether to engage in the development of renewable energy sources, whether to specialize in one specific source (as offshore wind generation). From this paper's point of view, it is important to note that whether to invest in innovation related to concentrating or distributed solar PV is one of the decisions made at this level. Moreover, investment decisions in new generation is made at this level (because it implies choosing among different technologies).

- Interaction \# 2: Collective-choice level in energy transitions - The second situation that we consider in this paper takes place at the collective-choice level. At this level, rule-makers decide on two basic dimensions: they organize procurement of energy and they set regulated prices (network tariffs). These decisions can be seen as the role as counterpart for market players that was defined at the constitutional level. On the other hand, firms make their contracting decisions. This implies for producers selling energy to customers, but also purchasing fuel when needed (e.g. purchasing gas to produce with gas-fired power plants). At the lower level, the operational level, firms and rule-makers decide how to implement decisions made at the upper level. That typically implies monitoring and regulated contract management for rule-makers, and production and consumption management for firms. This is represented in Figure 2.

Figure 2. Application of the traditional nested levels to the analysis of power markets, and representation of the change dynamics: level shifting strategies in energy systems.

The logic for our modeling approach is to consider that, after the technological trajectory and the regulatory framework are decided, firms need to coordinate activities to implement the expected 
strategies. In that view, they may face barriers to develop some of those strategies. Those barriers are sometimes associated with the regulatory framework. The previous logic establishes a link between regulatory frameworks and firms' decisions. However, rule-makers are not capable of foreseeing all aspects of the firms' decision-making process. Consequently, they also observe outcomes to deduce whether the regulatory framework is appropriate. Hence, both firms and rule-makers are observing outcomes, and they both apply evaluative criteria to understand them. Regardless the criteria that they used, if they deduce from the observation of outcomes that regulatory frameworks or technological trajectories are not adequate, they are able to engage in a process to change the upper level decisions. These decisions were termed level-shifting strategies in the previous subsection, see Figure 2. Note that this means that we do not consider some external policy-making process and hence we are able to establish a link between short-sighted evaluative criteria and carbon lock-in.

Therefore, we model the evolution of an electricity sector in the process of introducing distributed generation. We will consider three types of evaluative criteria: i) they observe only that electricity is produced by the cheapest available technology nowadays; ii) they observe that new technology is introduced just by observing new capacity (for instance by niche markets); and iii) they observe whether technology is adopted not just by observing capacity but by observing whether the rules in place are adapted to the new technology features.

\subsection{Implementation: The simulation model}

In this section, we propose the methodology to understand the interaction, which will be based on the system dynamics framework, (Forrester, 1968). Other applications of system dynamics developed to study investment in power markets are proposed in (Sánchez et al., 2007), (Cepeda and Finon, 2011), (López-Peña et al., 2009) and (Cepeda and Finon, 2013). We simplify technology dynamics in order to analyze in more detail the institutional dimension. Hence, we consider a very simplified situation where all technologies to produce electricity are mature ones, and the only possible technology evolution is related to solar PV. Besides, we also simplify these dynamics by summarizing them through a learning 
curve. In particular, we use an experience curve, (Rosenberg, 1982), which relates unit costs reductions to cumulative deployment of technology. R\&D policies are implicit in this representation.

The quantitative analysis of the question posed in this paper is performed using the following (very simplified) description of the decision-making process:

1. With future expectations, players calculate future income streams. They will be calculated by using the simulation model described in the Appendix.

2. With learning curves, players calculate technology costs. Together with possible externality policies (e.g. carbon taxes), they calculate cash flows.

3. With regulation, players calculate discount rates. Rules define possible barriers that we simplify by including them in the perceived discount rate (not necessarily and equilibrium one). Together with possible technology policies, they decide on investment decisions.

Figure 3. Framework to analyze renewable policies.

As the technology is the same (or at least that is what policy makers believe), one should observe the same penetration. If policy makers do not observe that, they revise their policy. So at the beginning of each step of the simulation, regulators may decide to equalize discount rates. They do so if investments decided by the two technologies have differences above a certain tolerance. Initially, utility-scale PV enjoys better discount rates. If policies are not revised, distributed solar never enters the market (during the simulation scope).

\subsubsection{Representation of power system operation}

One of the main characteristics of the Brazilian power system organization is that the unit commitment is decided centrally. From this papers' point of view, that eliminates the need of representing strategic interaction between players (each of whom would own a particular generation portfolio). Consequently, we will consider aggregately both supply and demand (which allows simpler computation), at the cost of losing accuracy in the representation of system technical characteristics. 
We will consider supply and demand concentrated in four nodes: SE (the largest node, where the majority of the demand is located), S, NE, and N. On the supply side, we will consider aggregately all generation at the node produced by technology. For instance, at node SE (South-East), we will consider four thermal power plants: one for all production from coal-fired power plants, one for gas-fired power plants, one for oil-fired power plants, and one for nuclear production. Additionally, at each of the four nodes, we will consider the corresponding hydro-based production. All required data is collected from the national planning report, (EPE, 2014a).

Two additional generation technologies are relevant in our study. On the one hand, wind production is a non-dispatchable technology. That is, power producers cannot decide when to produce with the wind farm, they are forced to produce when the wind blows. Consequently, wind production will be a special technology that will not be subject to producers' decisions. Instead, it will be understood as a stochastic input that modifies the actual system demand. In addition, we will consider that there is no solar capacity installed in the system (the capacity installed so far is small enough to be disregarded). Consequently, all solar capacity in the system will be the result of producers' investment decisions, which are in turn the result of the expectation of future system marginal costs.

Finally, it is necessary to transform the fuel prices into thermal plants variable costs. We model such transformation, in the study, as the price of just one forward contract of the curve multiplied by the efficiency of the plant. In particular, the variable cost will be the forward price of the contract expiring in three months, multiplied by the efficiency. The rationale behind this is that power producers need at least three months to get additional fuel, so their variable cost is the cost of refueling.

Next we describe the modeling approach, and further details are provided in the Appendix.

- Demand, wind production and hydro power inflows: Besides the data defining generation capacity, our modeling approach considers fundamental drives to define system marginal costs. The fundamental drivers considered in this paper are: (i) demand, (ii) wind production, (iii) inflows to hydro plants, which will be ultimately transformed into capacity of their reservoir, and (iv) fuel prices. This subsection deals 
with the first three drivers, and we leave the fourth driver for the next subsection. Our approach to model them is based on considering them as functional data. In order to model those functions and estimate them from historical data, we use Generalized Additive Models, (Hastie and Tibshirani, 1990). We consider each of the variables (demand, wind production and water inflows) as functional data. That is, each observation will be considered as part of function that describes the variation of the variable over one year. In that view, each point in the sample will depend on two variables: year and month. Consequently, our generalized additive model will be expressed by the following model:

$$
E[Y / \text { Year }, \text { Month }]=f_{\text {year }}(\text { Year })+f_{\text {month }}(\text { Month })
$$

Besides, each of the components will be modeled by a smoothing spline. As an instance, we show the fits obtained by the previous procedure for the wind Production at NE (North East). It has grown markedly in the last decade, as can be observed in the left panel of Figure 4. In it, we represent the smooth component relating wind production and yearly evolution.

Figure 4. Smooth components of the GAM for the wind production at NE.

- Representing financial data on fuel prices: We use of the methodology developed in (Heath et al., 1992) and applied, among many others, in (Koekebakker and Ollmar, 2005), where the forward curve of the NordPool is in studied, or in (Clewlow and Strickland, 1999), where the forward curves in the NYMEX gas and oil markets are analyzed. The main results are given by the following model:

$$
\frac{d F_{t, t+s}}{F_{t, t+s}}=\sum_{z} \sigma_{s}^{z} d W_{t}^{z}
$$

where the subscript $s=T-t$ denotes the time to expiration of the forward contract. Thus, we will consider the random shocks governing the dynamics of the forward curve as functions only of the timeto-expiration time, i.e. independent of the quotation date $t$.

The most used method to estimate the functions $\sigma_{s}^{z}$ is using Principal Component Analysis (PCA). The basic idea behind that approach is that frequently a small number of principal components suffice to 
explain most of the variability in the forward curves. However, the complex characteristics of energy forward curves make difficult to use linear methods as PCA. Hence, we will estimate the functions using non-linear techniques. We will use a Generalized Additive Model (GAM) approach, along the lines of the models used for the rest of fundamental drivers. The idea is to extend the multiple linear regression context by using nonlinear functions instead. When applied to estimating forward curves, we will use the following regression problem as estimator of the forward curve:

$$
E[Y / X]=f_{\text {year }}(\text { Year })+f_{\text {month }}(\text { Month })+f_{\text {exp }}(\text { Expiration })
$$

The variable 'Expiration' represents the time to expiration of each of the contracts that conform the forward curve. Along the lines of the models for the other fundamental drivers, each $f_{i}\left(X_{i}\right)$ will be a smoothing spline, fit by means of the backfitting algorithm. Consequently, each component $f_{i}\left(X_{i}\right)$ will represent one of the functions driving the evolution of the forward curve, $F_{t, t+s}$.

Figure 5. Smooth components of the Generalized Additive Model used to represent gas forward curves.

- A model to optimize the Brazilian power system operation: We rely on the methodology developed in (Barquín and Vazquez, 2008) to model the power system operation. Consider the following notation:

- $\boldsymbol{q}_{t, i}$ is the vector of total outputs of firm $i$ at time $t: \boldsymbol{q}_{t, i}=\left[\begin{array}{c}q_{t, i, 1} \\ \vdots \\ q_{t, i, N}\end{array}\right]$

- $\boldsymbol{C}_{t, i}\left(\boldsymbol{q}_{t, i}\right)$ is the generation cost of firm $i$ at time $t$ :

$$
\boldsymbol{C}_{t, i}\left(\boldsymbol{q}_{t, i}\right)=\left[\begin{array}{c}
C_{t, i, 1}\left(q_{t, i, 1}\right) \\
\vdots \\
C_{t, i, N}\left(q_{t, i, N}\right)
\end{array}\right]
$$

- $\boldsymbol{q}_{i}^{\max }$ is the maximum output of firm $i$

$$
\boldsymbol{q}_{i}^{\max }=\left[\begin{array}{c}
q_{i, 1}^{\max } \\
\vdots \\
q_{i, N}^{\max }
\end{array}\right]
$$


- $\boldsymbol{\rho}_{t, i}^{\min }$ and $\boldsymbol{\rho}_{t, i}^{\max }$ are the Lagrange multipliers corresponding to minimum and maximum output constraints, respectively, at time $t$ :

$$
\boldsymbol{\rho}_{t, i}^{\min }=\left[\begin{array}{c}
\rho_{t, i, 1}^{\min } \\
\vdots \\
\rho_{t, i, N}^{\min }
\end{array}\right], \boldsymbol{\rho}_{t, i}^{\max }=\left[\begin{array}{c}
\rho_{t, i, 1}^{\max } \\
\vdots \\
\rho_{t, i, N}^{\max }
\end{array}\right]
$$

- $\boldsymbol{\pi}_{t}$ is the market price at time $t$ :

$$
\boldsymbol{\pi}_{t}=\left[\begin{array}{c}
\pi_{t, 1} \\
\vdots \\
\pi_{t, N}
\end{array}\right]
$$

- $\boldsymbol{f}_{t}$ is the flow through the lines at time $t$ :

$$
\boldsymbol{f}_{t}=\left[\begin{array}{c}
f_{t, 1} \\
\vdots \\
f_{t, J}
\end{array}\right]
$$

- $\boldsymbol{f}^{\text {min }}$ and $\boldsymbol{f}^{\max }$ contains the limits for the flows

$$
\boldsymbol{f}^{\min }=\left[\begin{array}{c}
f_{1}^{\min } \\
\vdots \\
f_{J}^{\min }
\end{array}\right], \boldsymbol{f}^{\max }=\left[\begin{array}{c}
f_{1}^{\max } \\
\vdots \\
f_{J}^{\max }
\end{array}\right]
$$

- $\mathcal{M}$ represents the nodes-lines incidence matrix, whose element $\mathcal{M}_{n, j}$ is 1 if the line $j$ is leaving the node $n,-1$ if the line is arriving at node $n$ and 0 otherwise

- $\boldsymbol{\varphi}_{t}$ is a vector containing the voltage phases at every bus, but the bus 1 whose phase is set to zero

$$
\boldsymbol{\varphi}_{t}=\left[\begin{array}{c}
0 \\
\varphi_{t, 2} \\
\vdots \\
\varphi_{t, N}
\end{array}\right]
$$

- $\mathcal{F}$ is the matrix, obtained from the admittance data, relating flows and voltage phases

- $\mathcal{T}_{i}$ is a 0-1 matrix, which maps firms into buses. That is, $\mathcal{T}_{i}(n, i)=1$ means that firm $i$ is placed at bus $n$ 
The above notation allows representing the equilibrium problem as (see Appendix for details on the derivation of the equilibrium conditions):

$$
\begin{array}{rll}
\min _{q_{t, i}, D_{t, n}, f_{t, j}, \varphi_{t, n}} & \sum_{t, i} \boldsymbol{C}_{t, i}\left(\boldsymbol{q}_{t, i}\right)-U\left(\boldsymbol{D}_{t}\right) & \\
\text { s.t. } & \boldsymbol{D}_{t}+\mathcal{M} \boldsymbol{f}_{t}=\sum_{i} \mathcal{T}_{i} \boldsymbol{q}_{t, i} & : \boldsymbol{\pi}_{t} \\
& 0 \leq \boldsymbol{q}_{t, i} \leq \boldsymbol{q}_{i}^{\text {max }} & : \boldsymbol{\rho}_{t, i}^{\text {min }}, \boldsymbol{\rho}_{t, i}^{\text {max }} \\
& 0 \leq \boldsymbol{q}_{a, i}^{h} \leq \boldsymbol{E}_{i}^{\text {max }} & : \boldsymbol{\rho}_{a, i}^{\text {hmax }} \\
& \boldsymbol{f}_{t}=\mathcal{F} \boldsymbol{\varphi}_{t} & : \boldsymbol{\rho}_{t}^{\text {DC }} \\
& \boldsymbol{f}^{\text {min }} \leq \boldsymbol{f}_{t} \leq \boldsymbol{f}^{\text {max }} & : \boldsymbol{\rho}_{t}^{\text {min }}, \boldsymbol{\rho}_{t}^{\text {max }}
\end{array}
$$

\subsubsection{Investment decisions}

The next step, as represented in Error! Reference source not found. within our methodology framework, is transforming system operation results into expected cash flows. To that end, we will use the information contained in the optimization model, see the Appendix. In particular, the dual variable associated with the maximum output constraint $\boldsymbol{\rho}_{t, i}^{\max }$ represents, by definition, the reduction in system costs if one more unit of capacity were available. Hence, such dual variable represents directly the inframarginal rents of the corresponding power plant, see for instance (Vazquez et al., 2017) for a detailed description. Therefore, the dual variables $\boldsymbol{\rho}_{t, i}^{\max }$ will be the expected profits (income minus short-term costs) of each power plant at each point in time.

There are more inputs required to calculate the expected cash flows, both of which are related to including long-term effects. In principle, in order to obtain the expected cash flows, we need to add fixed costs to the previous expected profits (given by the dual variables $\boldsymbol{\rho}_{t, i}^{\max }$ ). Nonetheless, we consider two additional dimensions.

First, we consider 'learning curves' -we use the term 'learning' curve in a broad sense, not limiting them to represent learning-by-doing but also other types of learning (e.g. learning-by-using). The specific form in our model will be an experience curve, (Rosenberg, 1982), which relates unit costs reductions to cumulative deployment of technology, see for instance (Foxon, 2010) for a review of the application to 
climate change problems. In our context, learning processes of generation technologies will be represented by the learning rate, i.e. the reduction in unit costs for a doubling of cumulative output, using a power-law relationship between cost reductions and cumulative deployment. Besides, our methodology allows considering policies to reduce $\mathrm{CO} 2$ emissions (they would be an instance under the header 'externalities' in Error! Reference source not found.). In this paper, we use a carbon tax, which implies a reduction of profits for emitting technologies. On the other hand, cap-and-trade mechanisms would require introducing a $\mathrm{CO} 2$ price in the system operation model, and hence considering such price as a fundamental driver. In the case studies, we will consider that a carbon tax is in place.

The last step of the reasoning would be to model new investment decision-making. Besides the cash flows obtained above, we need to represent the discount rate for the investment decision. The analysis of section 2.2 .2 becomes crucial in this task.

Discount rates strongly depend on the maturity of the technology and the risks perceived in the investment cash flows. In that view, we will consider a higher discount rate for solar projects that for the construction of gas-fired power plants. In addition, one of the main determinants of the cash flow risk is the institutional setting. As shown in section 2.2.2, distributed generation faces, in Brazil, a less attractive environment for investment, so we will consider (initially) a higher discount rate for distributed generation. The logic for this is that they face higher risks associated with their cash flows. This is a very simplified representation of the factors affecting distributed generation cash flows. More detailed representations should include increased costs associated with particular regulations. Nonetheless, the simplification is still interesting in the sense that allows us creating asymmetries among technologies. That is, we focus on relative costs caused by regulations (i.e. one technology that ends up being cheaper because a certain set of rules), rather than to represent realistic cash flows.

Finally, the amount of generation defined by the niche market policy is introduced in the system. That is, we consider the niche market policy to ensure profitability of the corresponding investment, thus 
constituting a technology-specific policy aimed at any kind of solar PV (utility-scale ones and any other PV technology).

\subsubsection{Feedbacks (positive or negative)}

There are three main feedbacks in our methodology, as shown in Figure 3. First, the simulation of the power system for the next year must take into account new generation capacity (either from solar or gasfired power plants). Second, the amount of installed capacity for each technology, or equivalently its deployment, represents advancing in the experience curve. Consequently, the next step of the simulation, unit investment costs will be updated according to such experience. Third, we take into account the possibility that regulators and policy-makers observe the market results and modify policies accordingly. This will be done only in the case 3 considered in section 4.3 . That will eventually result in the modification of the relevant discount rate, and hence it will critically affect investment decisions.

\section{Analysis of the dynamics of the Brazilian power sector}

In order to facilitate the exposition, we will limit the possibilities of investment in fossil-fuel-fired power plants to investment in gas-fired power plants. These investments will be compared to investment in new (and renewable) technology. As wind production has increased significantly in Brazil during the last decade, we will consider that the new technology entering the market is solar PV generation. Note that the problem is a simplification, as there are more technologies that can be chosen. For instance, biomass is an effective competitor for solar technologies in Brazil. We disregard this technology for the sake of simplification. Our objective in this case study is to analyze the dynamics of technology adoption observing a single new technology against incumbent technologies. But it is important to note that much of the analysis performed in this case study can be extended to biomass. In any case, the analysis of the competition between solar PV and biomass will be part of future research.

Besides, we will differentiate between utility-scale PV and distributed-generation PV. Hence, investors in our model will choose among one of those three technologies. In that context, investors consider only whether a unit investment is profitable under the previous conditions. The size of the power plant to be 
built is defined exogenously. We will study three different cases. In the first one, we consider that there is no technology policy in place. This first case represents a regulator that is only concerned with the "environmental externality", which is represented by an extra cost. Hence, policy makers use the system marginal cost as the only criterion to assess outcomes. The second case analyzes the behavior of regulators concerned with the "innovation externality" in addition to the "environmental externality". They use niche markets, and they assess industry outcomes by observing the installed capacity in solar PV. Finally, we consider regulators concerned with technological lock-in, and they react if asymmetries in the adoption of utility-scale PV and distributed generation PV are observed.

\subsection{Case 1}

We first analyzed the case where there is no technology policy in place. In this case, we assume the evaluation criteria for policy makers to decide to maintain or change the rules is just the electricity price. From that point of view, this case will confirm that, in order to achieve the introduction of solar technologies in the power system, some kind of policy is required. This will confirm the analysis developed in the first sections of the paper. In that view, this case will serve as a test of the model parameters. This first simple case can be summarized by considering that investment takes place under the following conditions:

- Gas-fired power plants have a minimum size of $7000 \mathrm{MW}$ the first 5 years of the time scope. This represents higher needs of investment associated with large increases of demand. Those investments are valued at a discount of 15\%. Besides, as gas-fired power plants are CO2 emitters, they are penalized with a carbon tax, which results in a decrease of $15 \%$ of power plant income streams

- Solar power plants are built with a minimum size of $50 \mathrm{MW}$, and are valued at a discount of $20 \%$ 
No additional features are added in this case, In particular, it does not include niche markets, and regulators and policy-makers do not react to observed outcomes of the market. In this scenario, Figure 6 depicts the investment in gas-fired power plants at each node of the system.

Figure 6. Investment in gas-fired power plants over the complete time scope. Note that for the $\mathrm{N}$ node, investment never reaches zero.

In addition, we observe that solar power plants never enter the market, as shown in Figure 7, which considers together utility-scale PV and distributed-generation PV. Except for an isolated investment in one of the first years at the SE, no investment in solar plants is achieved.

Figure 7. Investment in solar power plants (considered utility-scale and distributed PV together).

In summary, this case shows that, in absence of some policy to facilitate the insertion of new technology, the high unit costs of the new solar technology will preclude its penetration in the Brazilian power system. Next cases will introduce such policies.

\subsection{Case 2}

In the second case, we analyze whether the introduction of a solar policy can modify the previous results. The evaluation criteria in this case is the increase of the capacity of any solar generation. The basic characteristics of the previous case are reproduced here:

- Gas-fired power plants have a minimum size of $7000 \mathrm{MW}$ the first 5 years of the time scope. This represents higher needs of investment associated with large increases of demand. Those investments are valued at a discount of 15\%. Besides, as gas-fired power plants are CO2 emitters, they are penalized with a carbon tax, which results in a decrease of $15 \%$ of power plant income streams

- Utility-scale solar power plants are built with a minimum size of $50 \mathrm{MW}$, and are valued at a discount of $20 \%$ 
- Distributed-generation PV faces a less favorable environment (see section 2.2.2) so they are valued at a discount rate of $25 \%$

In this case we introduce a niche market policy. This represents well the current policy solutions implemented in Brazil as well as the ones put in place for the introduction of wind power. The Brazilian system is carrying out dedicated auctions for solar technology (as it did previously for wind technology), which is in fact a niche market policy: the auction represents a firm long-term contract, which consequently lock-in demand to develop the technology. The representation of such policy in our methodology is as follows:

- There are niche markets in place during the first 6 years of the simulation scope. They are represented by an investment in utility-scale solar plants of $100 \mathrm{MW}$ without cost

Consequently, we investigate in this case whether the policy dedicated to utility-scale PV, which will reduce unit costs of both technologies (both technologies share the same experience curve), is enough to allow the introduction of distributed generation (at less favorable discount rates).

Figure 8. Investment in utility-scale PV over the time scope.

Figure 8 shows the utility-scale PV capacity installed over the simulation scope. We observe that utilityscale PV is introduced consistently at the N node (North).

Figure 9. Fixed cost for solar technology over the time scope. The decay shows the effects of the learning process.

In addition, Figure 9 shows the effects of the niche market policy on the experience curve of solar technology. The steep decrease of the first years of the simulation is associated with the niche market policy (it lasted 6 years). After that, utility-scale PV plants are introduced in the market competitively. It is worth to note that this result has an analogue in the evolution of wind power in Brazil, where the previous dynamic was actually observed in the market (several dedicated long-term auctions followed by several competitive auction where wind power plants won the contracts). The rationale behind the Brazilian approach is to mimic those results with solar power plants. 
Figure 10. Investment in solar PV (distributed technology).

However, Figure 10 shows the results for distributed generation. Except for an isolated investment the last year of the simulation, the technology is never introduced. This was one of the main points raised in section 2.2.2: the difficulties faced by distributed generation precludes its introduction in the market, even if it benefits from the niche market policy.

\subsection{Case 3}

In this last case, we show the need for institutional adaptation. The idea behind this case is to show that, frequently, the problem institutions were supposed to solve when they were designed changes over time. In particular, we will model the response of regulators and policy makers to the fact that the policy designed to promote solar generation introduced barriers for one of the possible solar technologies. In this case the policy makers' evaluation criteria is not just the introduction of solar (capacity) but also the coherence between the market design rules and the technical characteristics of the new technology.

The starting point is the case described above: there is a niche market in place that reduces the unit costs of both technologies; but the first one (utility-scale PV), which enjoys favorable conditions associated with the institutional setting, is valued at a discount rate of $20 \%$; the other one (distributed-generation PV), with less favorable conditions, faces a discount rate of $25 \%$.

In this situation, policy makers can observe market investment in solar technologies to assess whether the policy is successful. If the amount of utility-scale PV is higher than double the amount of distributedgeneration PV, they establish a discount of $20 \%$ (representing that they eliminate barriers to distributed generation). Note that we do not assume that distributed generation PV is cheaper than utility-scale PV.

Figure 11. Investment in distributed solar generation.

Figure 11 shows that, when regulators and policy makers respond to observed conditions, distributedgeneration PV is effectively introduced in the system. It shows that the technology is consistently introduced at $\mathrm{N}$, as investment levels are maintained years after the niche market policy disappears. 
Figure 12. Comparison between the learning processes in cases 2 and 3.

Finally, Figure 12 compares the cost reduction (through experience curves) obtained in cases 2 and 3. It can be observed that the introduction of distributed-generation PV solar improves the learning process and hence reduces costs. Consequently, if regulators and policy makers respond to the observed difficulty of distributed generation to enter the market, it finally enters and obtains a larger amount of installed solar megawatts.

\subsection{Analysis}

The first case showed that, in absence of some policy to facilitate the adoption of the new technology, its high unit costs will preclude its penetration in the Brazilian power system. The second case investigated whether a niche-market policy dedicated to utility-scale PV, which reduces unit costs of both utility-scale PV and distributed-generation PV, is enough to allow the introduction of distributed generation PV. We found that, even with the extra benefits of the niche-market policy, regulatory barriers preclude the adoption of distributed generation PV. The third case shows that, when regulators and policy makers respond to observed conditions, distributed-generation PV is effectively introduced in the system. Consequently, our cases show that technological lock-in is closely associated with the way in which regulators adapt to changing conditions.

Note that we do not perform sensitivity analyses of these simulations, especially regarding the discount rates. Consequently, we should be cautious when drawing lessons from the studies. The case study does not prove that technological lock in will happen but that technological lock in might happen. Stronger conclusions would require more robust numerical analyses of model parameters, including sensitivity analyses of discount rates.

\section{Conclusion and policy implications}

Based on the economic theory, we model the regulation choice as a combination of regulators' beliefs and the feedback they obtain observing system outcomes, which makes them adapt the regulatory 
framework. As consequence, the evaluative criteria play a central role in the rules adaptation and thus the technological adoption and innovation effort. If criteria are myopic, potential technological pathways can be blocked as consequence of regulatory rigidity. Hence, we show that the use of the myopic criteria to evaluate outcomes is a relevant piece in the creation of a lock-in. From a policy-making point of view, our simplified study points at the importance of considering the way in which regulators evaluate the industry outcomes. Most of studies consider regulation as a static set of rules defined exogenously to the system. We introduce a framework where regulators interact dynamically with the industry resulting in the joint evolution of regulation and industry characteristics. We propose a way to operationalize it by considering that the primitive of study is not regulators' decisions but their evaluative criteria. If regulatory decisions are independent, the evaluative criteria used in this representation is a policy decision. Thus, the general policy implication of this paper is that the choice of evaluative criteria is the key instrument in the combination of technological and institutional dynamics, because the evaluative criteria are the variables that allow institutional adaptability when facing market dynamics. And the choice of evaluative criteria should be based on policy objectives, as they may determine regulatory, technological and energy mix paths.

In addition, in order to obtain concrete policy implications for the Brazilian system, we have developed an analytical framework to study in a quantitative manner the effects of institutional adaptation. In the simulation of a stylized Brazilian system, we have shown that policies are needed in order to obtain the introduction of solar PV in the Brazilian generation matrix (as shown by case 1). In addition, we have shown that the policies currently implemented create barriers to distributed solar technologies (case 2). Actually, we have shown that such barriers are created along three basic dimensions: i) the way in which the system is planned tends to attribute a residual role for distributed generation; ii) because distributed generation cannot participate in auctions, it cannot underwrite PPAs and hence risk exposure is significantly larger; iii) because it cannot participate in auctions, distributed generation does not have access to cheap financing from the BNDES (the Brazilian Development Bank). Finally, we have shown that the introduction of distributed solar PV requires regulatory institutions to act on those barriers (case 3). 
In that sense, we identify that policies originally aimed at facilitating the introduction of solar PV are creating a technological lock-in to utility-scale solar PV.

This does not necessarily imply that regulatory institutions were wrong when they were implemented. The current institutional setting was designed when distributed generation was not a viable option for power investors. However, when technology develops, regulators need to adapt accordingly, so that market rules do take distributed solar PV into account adequately. In the application to the Brazilian power sector, we observe that only when regulators consider the possibility that the system is locked-in to centralized production technologies (instead of when they just consider the carbon lock-in) they manage to avoid barriers to distributed generation based on solar PV. Consequently, we show the importance that regulators revise, besides their designs, the evaluative criteria with which they observe the industry in order to be more responsible of the evolution of technological path. Differently put, one basic step in the future development of the Brazilian system, which needs to take place before a change in the rules, is the definition of the objectives that are being pursued. Our simulation showed three of them: case 1) regulators not concerned with technology dynamics; b) regulators not concerned with technological lock-in; and c) regulators considering both technology dynamics and technological lock-in.

Future research must pay attention to the way in which evaluative criteria are formed, and how those criteria are transformed into regulatory actions.

\section{Acknowledgement}

We thank Ronaldo Bicalho and Gustavo Andreão for fruitful discussions that helped shaping the ideas developed herein. We are also grateful to the NIETI at UFF, which provided significant insight regarding technology policy. We also benefited from participants at the 2015 ISNIE Conference and at the Workshop "Challenges Of The Power Industry: Policies, Goals And Implementation" at the Fluminense Federal University. We also thank three anonymous referees for considerably helpful comments. This research has been partly funded by CAPES/BRASIL through the Science without Borders post-doctoral program. 


\section{References}

Andreao, G., Hallack, M., Vazquez, M., 2017. The Relationship Between Finance and Industrial Policy in the Promotion of Renewable Technology: The Challenges to Promote Photovoltaic in Brazil. Presented at the 40th Annual IAEE International Conference, Singapore.

ANEEL, 2017a. Banco de Informações de geração.

ANEEL, 2017b. Resumo geral das usinas.

ANEEL, 2016. Resultado dos Leilões.

Arthur, W.B., 1994. Inductive reasoning and bounded rationality. The American economic review 84, 406-411.

Arthur, W.B., 1989. Competing technologies, increasing returns, and lock-in by historical events. The economic journal 99, 116-131.

Barquín, J., Vazquez, M., 2008. Cournot equilibrium calculation in power networks: An optimization approach with price response computation. Power Systems, IEEE Transactions on 23, 317-326.

Bauwens, T., 2016. Explaining the diversity of motivations behind community renewable energy. Energy Policy 93, 278-290.

Black, F., 1976. The pricing of commodity contracts. Journal of financial economics 3, 167-179.

Bolton, R., Foxon, T.J., 2013. Urban infrastructure dynamics: market regulation and the shaping of district energy in UK cities. Environment and Planning A 45, 2194-2211.

Borenstein, S., Bushnell, J., 1999. An empirical analysis of the potential for market power in California's electricity industry. The Journal of Industrial Economics 47, 285-323.

Cepeda, M., Finon, D., 2013. How to correct for long-term externalities of large-scale wind power development by a capacity mechanism? Energy Policy 61, 671-685.

Cepeda, M., Finon, D., 2011. Generation capacity adequacy in interdependent electricity markets. Energy Policy 39, 3128-3143.

Clewlow, L., Strickland, C., 1999. A multi-factor model for energy derivatives.

Crawford, S.E., Ostrom, E., 1995. A grammar of institutions. American Political Science Review 89, 582-600.

del Río, P., Linares, P., 2014. Back to the future? Rethinking auctions for renewable electricity support. Renewable and Sustainable Energy Reviews 35, 42-56.

Dosi, G., 1982. Technological paradigms and technological trajectories: a suggested interpretation of the determinants and directions of technical change. Research policy 11, 147-162.

EPE, 2014a. Plano Decenal de Expansão de Energia-PDE 202322.

EPE, 2014b. Plano decenal de expansão de energia 2024.

European Commission, 2014a. A Policy Framework for Climate and Energy in the Period from 2020 to 2030.

European Commission, 2014b. Guidelines on State Aid for Environmental Protection and Energy 2014-2020.

Forrester, J.W., 1968. Industrial dynamics-after the first decade. Management Science 14, 398-415.

Foxon, T.J., 2011. A coevolutionary framework for analysing a transition to a sustainable low carbon economy. Ecological Economics 70, 2258-2267.

Foxon, T.J., 2010. Stimulating investment in energy materials and technologies to combat climate change: an overview of learning curve analysis and niche market support. Philosophical Transactions of the Royal Society of London A: Mathematical, Physical and Engineering Sciences 368, 3469-3483.

Gawel, E., Lehmann, P., Purkus, A., Söderholm, P., Witte, K., 2017. Rationales for technology-specific RES support and their relevance for German policy. Energy Policy 102, 16-26.

Giordano, V., Fulli, G., 2012. A business case for Smart Grid technologies: A systemic perspective. Energy Policy 40, 252-259.

Haas, R., Panzer, C., Resch, G., Ragwitz, M., Reece, G., Held, A., 2011. A historical review of promotion strategies for electricity from renewable energy sources in EU countries. Renewable and sustainable energy reviews 15, 1003-1034.

Hall, S., Roelich, K., 2016. Business model innovation in electricity supply markets: The role of complex value in the United Kingdom. Energy Policy 92, 286-298.

Hammons, T.J., Barroso, L.A., Rudnick, H., 2011. Latin America: market mechanisms and supply adequacy in power sector reforms. Energy Systems 2, 83-111.

Hardin, G., 1968. The tragedy of the commons. science 162, 1243-1248.

Hashimoto, H., 1985. A spatial Nash equilibrium model, in: Spatial Price Equilibrium: Advances in Theory, Computation and Application. P. Harker, Springer-Verlag, Berlin, pp. 20-40.

Hastie, T.J., Tibshirani, R.J., 1990. Generalized additive models. CRC press. 
Heath, D., Jarrow, R., Morton, A., others, 1992. Bond pricing and the term structure of interest rates: A new methodology for contingent claims valuation. Econometrica 60, 77-105.

Iychettira, K.K., Hakvoort, R.A., Linares, P., 2017. Towards a comprehensive policy for electricity from renewable energy: An approach for policy design. Energy Policy 106, 169-182.

Jacobsson, S., Lauber, V., 2006. The politics and policy of energy system transformation-explaining the German diffusion of renewable energy technology. Energy policy 34, 256-276.

Jaffe, A.B., Newell, R.G., Stavins, R.N., 2005. A tale of two market failures: Technology and environmental policy. Ecological economics 54, 164-174.

Koekebakker, S., Ollmar, F., 2005. Forward curve dynamics in the Nordic electricity market. Managerial Finance 31, 73-94.

Künneke, R.W., 2008. Institutional reform and technological practice: the case of electricity. Industrial and corporate change 17, 233-265.

Langlois, R.N., Robertson, P.L., 2002. Firms, markets and economic change: a dynamic theory of business institutions. Routledge.

López-Peña, Á., Centeno, E., Barquín, J., 2009. Long term issues to be addressed by regulators in liberalised electricity systems: generation adequacy and indicative planning. Justification, available mechanisms, and a simulation study on some concrete policies.

Lopez-Polo, A., Haas, R., Panzer, C., Auer, H., 2012. Prospects for grid-parity of photovoltaics due to effective promotion schemes in major countries, in: Power and Energy Engineering Conference (APPEEC), 2012 Asia-Pacific. IEEE, pp. 1-4.

Mello, J., 2014. Inserção da geração distribuída fotovoltaica no sistema eléctrico brasileiro: política energética e mecanismos de incentivo (Master Thesis). Universiadade Federal Fluminense, Niterói, Brasil.

Nill, J., Kemp, R., 2009. Evolutionary approaches for sustainable innovation policies: From niche to paradigm? Research policy 38, 668-680.

Ostrom, E., 2009. Understanding institutional diversity. Princeton university press.

Ostrom, E., Gardner, R., Walker, J., 1994. Rules, games, and common-pool resources. University of Michigan Press.

Perez, C., 2009. Technological revolutions and techno-economic paradigms. Cambridge journal of economics bep051.

Pérez-Arriaga, I.J., Linares, P., 2008. Markets vs. regulation: A role for indicative energy planning. The Energy Journal 29, 149-164.

Reuters Brasil, 2016. Francesa EDF compra 80\% de usinas fotovoltaicas da Canadian Solar em Minas Gerais. Reuters Brasil.

Rosenberg, N., 1982. Inside the black box: technology and economics. Cambridge University Press.

Sánchez, J.J., Barquín, J., Centeno, E., López-Peña, A., 2007. System Dynamics models for generation expansion planning in a competitive framework: oligopoly and market power representation, in: Proceedings of the 25th International Conference of the System Dynamic Society, Boston.

Simon, H.A., 1959. Theories of decision-making in economics and behavioral science. The American economic review $49,253-283$.

Tinbergen, J., 1952. On the theory of economic policy.

Tolmasquim, M.T., 2012. Power Sector Reform in Brazil. Synergia.

Vazquez, C., Hallack, M., Vazquez, M., 2017. Price computation in electricity auctions with complex rules: An analysis of investment signals. Energy Policy 105, 550-561.

Williamson, O.E., 1998. Transaction cost economics: how it works; where it is headed. De economist 146, 23-58.

Witt, U., 1996. Innovations, externalities and the problem of economic progress. Public Choice 89, 113-130.

\section{Appendix - A model to optimize the Brazilian power system operation}

Many of the models aimed at representing the short-term market in power systems are defined by the solution of a static, non-cooperative game. The idea behind that approach is to define a game by means of the interaction of the firms involved in the market, each of whom solves a profit-maximizing problem taking into account that their decisions can effectively modify the market price. To complete the game, 
the market operator clears the market and calculates the price. Such approach, although may be not approximate enough in the case of the Brazilian market, will be useful to motivate our representation. We will consider, as a first step in the development of our methodology, the basic model for a short-term power market (see for instance (Borenstein and Bushnell, 1999) for a description of the rationale behind the approach). Let us define:

- $q_{i}$ is the total output of firm $i$

- $C_{i}\left(q_{i}\right)$ is the generation cost of firm $i$.

- $q_{i}^{\max }$ is the maximum output of firm $i$

- $\quad \rho_{i}^{\min }$ and $\rho_{i}^{\max }$ are the Lagrange multiplier corresponding to minimum and maximum output constraints, respectively

- $\pi$ is the equilibrium price

Each firm solves the following problem:

$$
\begin{aligned}
\max & \pi\left(q_{i}\right) q_{i}-C_{i}\left(q_{i}\right) \\
\text { s.t. } & 0 \leq q_{i} \leq q_{i}^{\max }: \rho_{i}^{\min }, \rho_{i}^{\max }
\end{aligned}
$$

We assume that the curves $C_{i}\left(q_{i}\right)$ are convex ones, in order to ensure that there is just one Nash equilibrium. Besides, in order to solve the Nash game we need equations that explain the behavior of the market operator. In this case, we will consider that the operator's clearing process is represented just by imposing that demand is equal to supply. This implies that we are considering an inelastic demand. Formally, $\sum_{i} q_{i}=D$. The set of equations that describe the Nash equilibrium are:

- Each firm's optimality with respect to output decisions (one optimality per firm)

$$
\pi\left(q_{i}\right)+\frac{\partial \pi}{\partial q_{i}} q_{i}-\frac{\partial C_{i}\left(q_{i}\right)}{\partial q_{i}}-\rho_{i}^{\max }+\rho_{i}^{\min }
$$

- Each firm's maximum output constraint 


$$
0 \leq q_{i} \leq q_{i}^{\max }
$$

- Each firm's complementarity conditions $(A \perp B$ denotes that $\mathrm{A}$ and $\mathrm{B}$ are complementary)

$$
\begin{gathered}
\left(q_{i}-q_{i}^{\max }\right) \perp \rho_{i}^{\max } \\
\left(0-q_{i}\right) \perp \rho_{i}^{\min }
\end{gathered}
$$

The equilibrium point, hence, has to fulfill the set of equations defined by the optimality conditions of every market participant, plus the market clearing equation $\sum_{i} q_{i}=D$. In order to solve the problem, we assume that the cost curve is known, so that $\frac{\partial c_{i}\left(q_{i}\right)}{\partial q_{i}}$ is known as well. We also assume that $\frac{\partial \pi}{\partial q_{i}}$ is a known parameter of the problem. We will also define $\theta_{i}=-\frac{\partial \pi}{\partial q_{i}}$.

Our approach to solve this equilibrium problem builds on the analysis developed in (Hashimoto, 1985). The central idea behind that work is that it is possible to use a single optimization program as a representation of the strategic interaction, because the optimality conditions of the appropriate optimization problem are the same as the equilibrium conditions of the previous game. The main advantage is that the optimization problem is easier to solve. It is easy to check that the equilibrium conditions defined above, when $\theta_{i}=-\frac{\partial \pi}{\partial q_{i}}$, are the same as the first-order optimality conditions of the following quadratic program:

$$
\begin{array}{lll}
\min & \sum_{i} \theta_{i} q_{i}^{2}+C\left(q_{i}\right) & \\
\text { s.t. } & 0 \leq q_{i} \leq q_{i}^{\text {max }} & : \rho_{i}^{\text {min }}, \rho_{i}^{\text {max }} \\
& \sum_{i} q_{i}=D & : \pi
\end{array}
$$

This basic model allows us present the reasoning applied to the Brazilian system. As shown in section 2.2.1, the institutional setting in Brazil defines that, once all energy is procured through the long-term auctions (and hence commercial agreements are formalized through long-term Power Purchase 
Agreements), the ONS (national system operator) takes control of the system. Such situation can be understood as a model where no market player have market power, and hence $\theta_{i}=0$. Consequently, our model for the short-term operation will be a system optimization, taking into account generation costs and technical constraints.

In power systems, technical constraints play a major role in the definition of the system marginal cost. In order to represent such technical constraints, we develop a multi-nodal version of the model described above. To do so, we consider the following extension, see (Barquín and Vazquez, 2008) for details:

$$
\begin{array}{lll}
\min & \sum_{t, i, n} C_{t, i, n}\left(q_{t, i, n}\right)-U\left(D_{t, n}\right) & \\
\text { s.t. } & D_{t, n}+\sum_{j} m_{n, j} f_{t, j}=\sum_{i} q_{t, i, n}: \pi_{t, n} \\
& 0 \leq q_{t, i, n} \leq q_{i, n}^{\max } & : \rho_{t, i, n}^{\min }, \rho_{t, i, n}^{\max } \\
& f_{t, j}=y_{j}\left(\varphi_{t, n}-\varphi_{t, n}\right) & : \rho_{t, j}^{D C} \\
& f_{j}^{\text {min }} \leq f_{t, j} \leq f_{j}^{\text {max }} & \rho_{t, j}^{\text {min }}, \rho_{t, j}^{\text {Fmax }}
\end{array}
$$

There are two major differences with respect to the former model. On the one hand, we have added the parameter $t$, in order to represent the time evolution of the relevant variables. On the other hand, we have also added the parameter $n$, in order to represent the node with which the variable is associated. We assume we have $n=\{1, \ldots, N\}$ nodes. Besides those two differences, we have new variables representing the power lines connecting the nodes, which will be indexed by $j=\{1, \ldots, J\}$. In the model above, the first constraint represents the balance equation in power networks: at each node, demand must be equal to supply plus the electricity flows leaving the node (either positive or negative). The last constraint represents the thermal limits of power lines, i.e. the maximum and minimum flows that it can transport. The second and third constraints represents the simplified physical characteristics of the power flow (this representation is often called 'DC power flow'). The above model can be written in vector form, in order to make clearer its relationship with the single-node model, by defining the following notation: 
- $\boldsymbol{q}_{t, i}$ is the vector of total outputs of firm $i$ at time $t: \boldsymbol{q}_{t, i}=\left[\begin{array}{c}q_{t, i, 1} \\ \vdots \\ q_{t, i, N}\end{array}\right]$

- $\boldsymbol{C}_{t, i}\left(\boldsymbol{q}_{t, i}\right)$ is the generation cost of firm $i$ at time $t$ :

$$
\boldsymbol{C}_{t, i}\left(\boldsymbol{q}_{t, i}\right)=\left[\begin{array}{c}
C_{t, i, 1}\left(q_{t, i, 1}\right) \\
\vdots \\
C_{t, i, N}\left(q_{t, i, N}\right)
\end{array}\right]
$$

- $\boldsymbol{q}_{i}^{\max }$ is the maximum output of firm $i$

$$
\boldsymbol{q}_{i}^{\max }=\left[\begin{array}{c}
q_{i, 1}^{\max } \\
\vdots \\
q_{i, N}^{\max }
\end{array}\right]
$$

- $\boldsymbol{\rho}_{t, i}^{\min }$ and $\boldsymbol{\rho}_{t, i}^{\max }$ are the Lagrange multipliers corresponding to minimum and maximum output constraints, respectively, at time $t$ :

$$
\boldsymbol{\rho}_{t, i}^{\min }=\left[\begin{array}{c}
\rho_{t, i, 1}^{\min } \\
\vdots \\
\rho_{t, i, N}^{\min }
\end{array}\right], \boldsymbol{\rho}_{t, i}^{\max }=\left[\begin{array}{c}
\rho_{t, i, 1}^{\max } \\
\vdots \\
\rho_{t, i, N}^{\max }
\end{array}\right]
$$

- $\boldsymbol{\pi}_{t}$ is the market price at time $t$ :

$$
\boldsymbol{\pi}_{t}=\left[\begin{array}{c}
\pi_{t, 1} \\
\vdots \\
\pi_{t, N}
\end{array}\right]
$$

- $\boldsymbol{f}_{t}$ is the flow through the lines at time $t$ :

$$
\boldsymbol{f}_{t}=\left[\begin{array}{c}
f_{t, 1} \\
\vdots \\
f_{t, J}
\end{array}\right]
$$

- $\boldsymbol{f}^{\min }$ and $\boldsymbol{f}^{\max }$ contains the limits for the flows

$$
\boldsymbol{f}^{\min }=\left[\begin{array}{c}
f_{1}^{\min } \\
\vdots \\
f_{J}^{\min }
\end{array}\right], \boldsymbol{f}^{\max }=\left[\begin{array}{c}
f_{1}^{\max } \\
\vdots \\
f_{J}^{\max }
\end{array}\right]
$$


- $\mathcal{M}$ represents the nodes-lines incidence matrix, whose element $\mathcal{M}_{n, j}$ is 1 if the line $j$ is leaving the node $n,-1$ if the line is arriving at node $n$ and 0 otherwise

- $\boldsymbol{\varphi}_{t}$ is a vector containing the voltage phases at every bus, but the bus 1 whose phase is set to zero

$$
\boldsymbol{\varphi}_{t}=\left[\begin{array}{c}
0 \\
\varphi_{t, 2} \\
\vdots \\
\varphi_{t, N}
\end{array}\right]
$$

- $\mathcal{F}$ is the matrix, obtained from the admittance data, relating flows and voltage phases

- $\mathcal{T}_{i}$ is a 0-1 matrix, which maps firms into buses. That is, $\mathcal{T}_{i}(n, i)=1$ means that firm $i$ is placed at bus $n$

The above notation allows representing the equilibrium problem as

$$
\begin{array}{rll}
\min _{q_{t, i}, D_{t, n}, t_{t, j}, \varphi_{t, n}} & \sum_{t, i} \boldsymbol{C}_{t, i}\left(\boldsymbol{q}_{t, i}\right)-U\left(\boldsymbol{D}_{t}\right) & \\
\text { s.t. } & \boldsymbol{D}_{t}+\mathcal{M} \boldsymbol{f}_{t}=\sum_{i} \mathcal{T}_{i} \boldsymbol{q}_{t, i}: \boldsymbol{\pi}_{t} \\
& 0 \leq \boldsymbol{q}_{t, i} \leq \boldsymbol{q}_{i}^{\max } & : \boldsymbol{\rho}_{t, i}^{\min }, \boldsymbol{\rho}_{t, i}^{\max } \\
& 0 \leq \boldsymbol{q}_{a, i}^{h} \leq \boldsymbol{E}_{i}^{\max } & : \boldsymbol{\rho}_{a, i}^{\text {max }} \\
& \boldsymbol{f}_{t}=\mathcal{F} \boldsymbol{\varphi}_{t} & : \boldsymbol{\rho}_{t}^{D C} \\
& \boldsymbol{f}^{\text {min }} \leq \boldsymbol{f}_{t} \leq \boldsymbol{f}^{\max } & : \boldsymbol{\rho}_{t}^{\text {min }}, \boldsymbol{\rho}_{t}^{\text {maxax }}
\end{array}
$$

In summary, each system operation scenario in our study will be formed by using fundamental driver scenarios in this model. Consequently, we will obtain, for each combination of fundamental drivers, at each point in time, the value of system marginal costs: they will be given by the (vector-valued) dual variable $\pi_{t}$. Nonetheless, in order to understand the dynamics of the power system, it is not only necessary to obtain marginal costs at each point in time, but, more importantly, the incentives to invest in each technology. 